https://doi.org/10.48009/1_iis_2010_533-537

\title{
THE ECONOMICS OF FEE-BASED IPHONE APPLICATIONS VERSUS FREE APPLICATIONS: TO CHARGE OR NOT TO CHARGE
}

\author{
Jennifer Breese-Vitelli, Robert Morris University, breesevitelli@ comcast.net \\ Philip Kim, Walsh University, pkim@ walsh,edu
}

\begin{abstract}
iPhone applications are a lucrative business for developers if an application gets noticed. This article explores the economic factors that should be considered when determining whether or not to charge for an iPhone application. A sample texting application is used to provide an example of what organizations can do to stay competitive and maximize profits.
\end{abstract}

Keywords: Social media, social networking, telecommunications, iPhone applications, \& economics

\section{INTRODUCTION}

The Apple iPhone has disrupted the balance of power with wireless carriers that historically viewed manufacturers as a lower class enslaved by the carrier; the carrier served as a feudal class king. The iPhone resulted in tripling the high profit data traffic of AT\&T and carriers began to shift the power balance. Carriers and manufacturers began to realize that the right phone can win customers and in turn result in higher revenue (Vogelstein, 2008). Apple released third party development software in February 2008 for developers to develop, test and distribute their applications for free or at a specified cost to the consumer. When there is a cost for the application, Apple takes $30 \%$ of the revenue with the developer getting $70 \%$. However, when the application is free, the developer needs only to pay a membership fee. As of January 2010, Apple announced that 3 billion applications have been downloaded from the App Store from users all over the world (Muller, 2010).

The purpose of this paper is to explore various factors that developers must take into consideration when developing an iPhone application. A decision must be made by the developer to either provide the application for free and find another way to receive compensation, or to charge for it and share the revenue with Apple,
Inc. upon each successful download Answering the five questions below proposed by Douglas W. Hubbard (2007) will aid in the explanation of the decision that constitutes the context of this paper. 1. What is the decision this is supposed to support? The supported decision is whether or not to charge for an application in lieu of giving the application away for free download and receiving advertising revenue.

2. What is really being measured?

What is the true profitability of advertising to generate downloads?.

3. Why does this matter to the decision being asked?

The decision to give away the application versus charging for the application influences how many consumers will download the application, and ultimately can determine whether the developer made the most profitable choice.

4. What research on this subject exists now?

Little is currently known comparing the differences in download frequencies between free applications and fee based applications. Further research will be conducted in this area to determine consumer behaviors.

5. What is the value of measuring it further?

The value of measuring downloads for free or fee based applications can be significant in that the profitability strategy could change if it is found that applications are downloaded more frequently when they are free (Hubbard, 2007). Additionally, Tessler (2010) notes there has been increased scrutiny of iPhone application development due to the recent legislation that allows iPhone users to "jailbreak" or unlock their iPhones to allow the device to be used on multiple carriers as well as download other applications outside of the Apple iTunes store (Kravets, 2010).

\section{Pricing}


The application Textnow is the number one downloaded social networking application and allows the consumer unlimited free text messaging to any phone in the United States without incurring carrier fees (iPad Apps/Games, n.d.). Currently, the application is $\$ .99$ for three months of service, $\$ 3.99$ for one year, and $\$ 7.99$ for a lifetime (EnFlick, n.d.). The average cost of developing an iPhone application is 200 hours (development + graphic design) at $\$ 50 / \mathrm{h}$ is approximately $\$ 10,000$ for development in the United States (Stackoverflow, n.d.). The cost can be lessened if the developer is offered a share of the end profits (Stackoverflow, n.d.). Additionally, offshore developers can be sought at a lower hourly development rate. While the current structure is fee based exploring the profitability of giving away the application and receiving advertising revenue will be explored.

The application fees are based on what the market will yield for the application. Application pricing has fallen since their initial gold rush. Premium applications, those $\$ 10$ and above, have all but disappeared from the market. The average cost of a top 100 application in February of 2009 was $\$ 2.55$ down from $\$ 3.15$ two months prior (Frommer, 2009). The article by Frommer (2009) speculates that the drops in fees are adding sales volume to aid developers in increasing revenue.

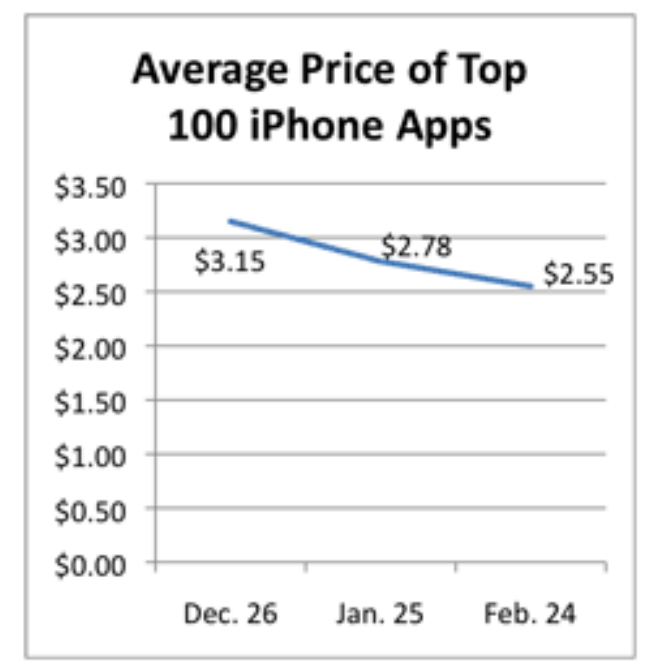

An article by Hughes (2009) cites the average iPhone application price around $\$ 2.85$. The author cites that the lower cost applications $\$ .99$ are usually associated with developers that are trying to gain acceptance and market share for their applications (Hughes, 2009).

\section{Stakeholders}

Stakeholders are: the wireless carrier, manufacturers, development team, and consumers. Wireless carriers, in this case AT\&T benefit from application development by additional customers being lured to the carrier mainly through the smartphone itself but secondarily through the extensive applications available through the iPhone. Manufactures like Apple benefit from the additional revenue stream developed through membership fees and profits derived from the sale of applications to consumers.

The development team is the group that develops the application and incurs the majority of the costs and the potential for windfall profits or losses. Consumers are stakeholders that obtain the application through purchasing or downloading the application for a fee or at no cost. Customers have a stake in the development of applications to increase the use of the original investment in the Smartphone device. The benefits as they apply to this application would be the monthly dollar amount savings for text messages sent through their existing cell phone plan. This paper does not address carriers as stakeholders, only manufacturers, development team, and consumers.

\section{Fixed Costs}

Fixed costs are those that are known from the inception of the project and will not change through the completion of the project. Fixed costs are often referred to as the set-up costs and do not change as the level of output increases. The fixed costs for the development of an application are the hours devoted by a developer to application development as stated above. The fee for Apple development membership is $\$ 99$ for their basic package and \$299 for the Enterprise package. For the purpose of our paper, the fee will be estimated to be an average of the two. Compared to the overall cost of the developer the membership fee can be determined as nominal. The budget used to purchase any capital equipment would include a Macintosh computer which the average advertised price is $\$ 1,300$. Advertising is separated into two categories; advertising costs incurred by the development team and advertising revenue brought in by the iPhone application. iPhone application advertising can range from zero to thousands of dollars; application advertising can vary greatly from a self-developed YouTube video to an advertisement on a major television network. 
Advertising revenue is derived from overall mobile advertising dollars estimated in 2009; it is expected that advertising revenue of $\$ 2,700$ will be garnered per day for a top 100 application.

\section{Variable Costs}

Variable costs are costs that can change as output levels change. Typically variable costs are related to the additional production of consumer goods per unit. The example used by Kingma (2001) uses an example of additional costs associated with pressing additional CD's or DVD's for consumer purchase (Kingma, 2001). This application does not have costs associated with additional units purchased. The variable costs for the development team are consumer reviews and the possibility of returns and the potential need for updates to the application. The variable cost for the consumer is how often the application is used and the degree to which it suits the purpose for which it was intended these variable costs will be quantified in the opportunity cost section below. The variable cost for the development team is the number of programming update hours which are estimated to be between two to four hours per month at a rate of $\$ 50$ per hour.

\section{Sunk Costs}

Sunk costs are costs that are irretrievable and unavoidable in the future. The sunk costs for the application development are membership fee for access to the development software. Additionally, sunk costs can be viewed as the man-hours the development team invested in the development of the software and the capital equipment. Sunk costs for the consumer are the cost of the application and the time they spend using the application.

\section{Marginal Costs}

Marginal costs for the developers and the manufacturers are costs that are incurred with producing one additional unit. In the sale of additional units of an iPhone application marginal costs are nominal; they are even less than they would be for comparable software program. In the example of a software program marginal costs are low, but the production of a CD for information transfer would need to be considered. In the example of the iPhone application, the electronic transfer of the application would not generate additional marginal costs to the carrier, manufacturer, or the developer. Opportunity Costs

Opportunity costs are the costs of the alternative opportunities that were relinquished to spend time working on the application or personal activities of their own by the development team. There are also opportunity costs for the consumer based on the time they could have spent searching, purchasing, and downloading other applications or time they could have spent engaged in other personal activities. An example of enumerating opportunity costs is derived by quantifying multitasking by the development team and the consumer. For the developer the opportunity cost would be their $\$ 50$ per hour rate plus the value of the time they sacrificed rather than engaging in other activities. The opportunity cost for the consumer is the price of the application plus the time they could have spent engaging in other activities both at an hourly rate for employment and personal activities. This author estimates that there are 85 texts sent per day an estimated ten seconds are spent per text with an average of 30 days per month for a three month period which equals 27.5 hours of texting per three month period.

Given the average cost of application plus the value of the time spent utilizing the application over three month period, the following is a projected value of opportunity cost to the consumer:

$\$ 4.32+(27.5$ hours per three month period $\mathrm{x}$ $\$ 15.00$ average value per hour) $=\$ 416.82$ consumer opportunity cost for a three month period.

\section{Economic Comparisons}

1. Consumer price per download $(80 \%$ of consumers purchasing the $\$ 0.99$ option, $15 \%$ of customers choosing the $\$ 3.99$, and $5 \%$ of customers purchasing the $\$ 7.99$ option) $\mathrm{X}$ the estimated number of downloads per month $X$ the number of months

$\$ 0.99 \times 120,000 \times 3$ months $=\$ 356,500$

$\$ 3.99 \times 22,500 \times 3$ months $=\$ 269,325$

$\$ 7.99 \times 7,500$ X 3 months $=\$ 179,775$

Total $\$ 805,600$

2. Average profit for advertising per day X 30 average days per month $\mathrm{X}$ number of months $(\$ 2,700 \times 30$ days per month $\times 2$ months $=$ $\$ 162,000)+(\$ 1,350 \times 30$ days $=\$ 40,500)=$ $\$ 202,500$ 


\section{Return on Investment}

(\$700 brochure development $+\$ 1,500$ website development, $+\$ 184$ Apple developer fee $+\$ 1,300$ capital equipment $+\$ 0$ YouTube video $=\$ 14,684$ total investment)

$\$ 805,600$ Value (from above)

$-\$ 14,684$ investment (from above) $=\$ 790,916$ or a $5,386 \%$ Return on investment

\section{DISCUSSION AND CONCLUSION}

Current literature is conflicting when addressing the increase in downloading free applications when compared to charging for the application. Some argue that it is always better to charge for the application because usage of a free application drops significantly after two months (Pinchmedia, 2009). Conflicting literature directly addresses that assumption and states that previous estimates do not consider that multiple advertisements are able to be placed on an application at one time refuting numbers estimated by Pinchmedia by a multiple of up to five times the original estimate (Kincaid, 2009).

The above calculations take into account both fee based and free application literature. Kincaid's (2009) estimates lean in the direction of providing free applications. Pinchmedia (2009) claims that usage, which is what advertisers base their payments on, for free applications decreases after a period of two months. The estimated downloads were based on the fact that the Textnow application is in the top 25 iPhone applications and that App Store are $\$ 200,000,000$ per month (Malik, 2009).

Based on the calculation comparisons if the application makes it into the rankings among the top 100 iPhone applications it is more profitable to charge a fee for the application rather than give the application away for free in order to receive advertising as the sole means of generating revenue. Conversely, there are approximately 50,000 applications available for download (Elmer-Dewitt, 2009), so the competition to achieving a top 100 application is extremely high. For those developers that have introduced successful applications, there is more of an opportunity to increase their revenue stream by charging a fee for the program, however for those that have not developed any applications, there should be a consideration to offer the application for free, thereby increasing the initial downloads, and the potential future long-term gain.

\section{REFERENCES}

Apple App Store Downloads Top Three Billion. (n.d.). Apple. Retrieved January 25, 2010, from http://www.apple.com/pr/library/2010/0 1/05appstore.html.

Elmer-Dewitt, P. (2009). Apple fact check: 50,000 iPhone apps? Fortune. Retrieved July 29, 2010, from http://tech.fortune.cnn.com/2009/06/10/a pple-fact-check-50000-iphone-apps/.

Frommer, D. (n.d.). iPhone App Prices Tanking. Business Insider. Retrieved April 4, 2010, from http://www.businessinsider.com/iphoneapp-prices-tanking-2009-2.

Hubbard, D. W. (2007). How to Measure Anything: Finding the Value of "Intangibles" in Business. New York, NY: Wiley.

Hughes, J. (2009, July 13). App Marketing 101: Pricing your iPhone App "Art and Science" | 148Apps.biz. 148Apps.biz | iPhone development news and information for the community, by the community. Retrieved April 4, 2010, from http://148apps.biz/app-marketing101-pricing-your-iphone-app-art-andscience/.

iPad Apps/Games : AppAdvice - AppBase. (n.d.). iPad Apps/Games : App Advice. Retrieved January 27, 2010, from http://appadvice.com/app/314716233.

Kincaid, J. (2009, May 6). Just How Much Money Can Free iPhone Apps Make? Quite A Bit. TechCrunch. Retrieved January 26, 2010, from http://www.techcrunch.com/2009/05/06/ just-how-much-money-can-free-iphoneapps-make-quite-a-bit/

Kingma, B. R. (2001). Economics of Information: A Guide to Economic and Cost-Benefit Analysis for Information Professionals (2 ed.). Englewood, Colorado: Libraries Unlimited. 
Kravets, D. (2010). Jailbreaking iPhone Legal, U.S. Government Says. ABC News. Retrieved July 30, 2010 from http://abcnews.go.com/Technology/usgovernment-jailbreaking-iphonelegal/story?id=11254253.

Malik, O. (2009, June 3). StatShot: Mobile Ad Spending to Grow to $\$ 5.7$ Billion. GigaOM. GigaOM. Retrieved January 31, 2010, from http://gigaom.com/2009/06/03/statshotmobile-ad-spending-to-grow-to-5-7billion/.

Pinch Media Blog . (2009, February 18). Pinch Media | Mobile Application Analytics | iPhone Analytics . Retrieved January 29, 2010 ,

from http://www.pinchmedia.com/appstoresecrets/.

Tessler, J. (2010). New gov't rules allow unapproved iPhone apps. Comcast News. Retrieved July 30, 2010 from http://www.comcast.net/articles/newsgeneral/20100726/US.TEC.Digital.Copyr ight/.

Vogelstein, F. (n.d.). The Untold Story: How the iPhone Blew Up the Wireless Industry. Wired News. Retrieved January 25, 2010, from

http://www.wired.com/gadgets/wireless/ magazine/16-

02/ff_iphone?currentPage $=4$. 